\title{
Linkage mapping and genome-wide association study reveals conservative QTL and candidate genes for Fusarium rot resistance in maize
}

Yabin $\mathrm{Wu}^{1+}$, Zijian Zhou ${ }^{1 \dagger}$, Chaopei Dong ${ }^{1 \dagger}$, Jiafa Chen ${ }^{3}$, Junqiang Ding ${ }^{1}$, Xuecai Zhang ${ }^{2}$, Cong Mu', Yuna Chen ${ }^{1}$, Xiaopeng $\mathrm{Li}^{1}$, Huimin $\mathrm{Li}^{1}$, Yanan Han ${ }^{1}$, Ruixia Wang ${ }^{1}$, Xiaodong Sun ${ }^{1}$, Jingjing $\mathrm{Li}^{1}$, Xiaodong Dai ${ }^{1}$, Weibin Song ${ }^{1}$, Wei Chen ${ }^{1}$ and Jianyu $\mathrm{Wu}^{1{ }^{*}}$ (D)

\begin{abstract}
Background: Fusarium ear rot (FER) caused by Fusarium verticillioides is a major disease of maize that reduces grain yield and quality globally. However, there have been few reports of major loci for FER were verified and cloned.

Result: To gain a comprehensive understanding of the genetic basis of natural variation in FER resistance, a recombinant inbred lines (RIL) population and one panel of inbred lines were used to map quantitative trait loci (QTL) for resistance. As a result, a total of 10 QTL were identified by linkage mapping under four environments, which were located on six chromosomes and explained 1.0-7.1\% of the phenotypic variation. Epistatic mapping detected four pairs of QTL that showed significant epistasis effects, explaining 2.1-3.0\% of the phenotypic variation. Additionally, 18 single nucleotide polymorphisms (SNPs) were identified across the whole genome by genomewide association study (GWAS) under five environments. Compared linkage and association mapping revealed five common intervals located on chromosomes 3, 4, and 5 associated with FER resistance, four of which were verified in different near-isogenic lines (NILS) populations. GWAS identified three candidate genes in these consistent intervals, which belonged to the Glutaredoxin protein family, actin-depolymerizing factors (ADFs), and AMP-binding proteins. In addition, two verified FER QTL regions were found consistent with Fusarium cob rot (FCR) and Fusarium seed rot (FSR).
\end{abstract}

Conclusions: These results revealed that multi pathways were involved in FER resistance, which was a complex trait that was controlled by multiple genes with minor effects, and provided important QTL and genes, which could be used in molecular breeding for resistance.

Keywords: Maize, Ear rot, Disease resistance, QTL, GWAS, Candidate gene

\footnotetext{
* Correspondence: wujianyu40@126.com

${ }^{\dagger}$ Yabin Wu, Zijian Zhou and Chaopei Dong contributed equally to this work.

${ }^{1}$ College of Agronomy, Henan Agricultural University, Zhengzhou 450002,

China

Full list of author information is available at the end of the article
}

(c) The Author(s). 2020 Open Access This article is licensed under a Creative Commons Attribution 4.0 International License, which permits use, sharing, adaptation, distribution and reproduction in any medium or format, as long as you give appropriate credit to the original author(s) and the source, provide a link to the Creative Commons licence, and indicate if changes were made. The images or other third party material in this article are included in the article's Creative Commons licence, unless indicated otherwise in a credit line to the material. If material is not included in the article's Creative Commons licence and your intended use is not permitted by statutory regulation or exceeds the permitted use, you will need to obtain permission directly from the copyright holder. To view a copy of this licence, visit http://creativecommons.org/licenses/by/4.0/. The Creative Commons Public Domain Dedication waiver (http://creativecommons.org/publicdomain/zero/1.0/) applies to the data made available in this article, unless otherwise stated in a credit line to the data. 


\section{Background}

Fusarium ear rot (FER) is one of the most important food and feed safety challenges in global maize production [1]. FER not only reduces the yield and quality of harvested maize but also is fatal to humans and animals, which consume the contaminated grain containing mycotoxins from some of the Fusarium spp. [2]. More than 10 Fusarium spp. can cause ear rot, among them, Fusarium verticillioides [synonym $F$. moniliforme Sheldon] and $F$. graminearum are the two most important species which can cause FER and Gibberella ear rot, respectively [3-5].

Fusarium verticillioides is an important maize pathogen in the world, which can lead to serious economic losses [6], particularly in China [7-9], the United States [10] and Southern Europe [11, 12]. Fusarium verticillioides can survive in plant residue, healthy seeds and soil, and initiate the infection of maize from seedborne or airborne inoculum, causing seedling disease, Fusarium stalk rot and FER $[10,13]$. FER usually occurs on physically injured kernels, random kernels, or groups of kernels, and consists of a light pink or white mold [10]. Infected maize kernels contain toxic fumonisin that is carcinogenic in humans and livestock and even causes porcine pulmonary edema, equine leukoencephalomalacia and rat hepatocarcinoma [14, 15]. Chemical and agronomic measures are not very effective in controlling FER [1]. The best strategy to control FER and to reduce the incidence of fumonisin contamination is breeding and promoting maize varieties with genetic resistance in order [16]. Moreover, in a RIL population from NC300 $\times$ B104, Robertson et al. [17] found the genomic and phenotypic correlations between FER and fumonisin accumulation is 0.87 and 0.64 , respectively, indicating that it was possible to select lines with reduced FER and fumonisin contamination at the same time [17]. These strategies require us to understand the genetics of resistance clearly, and identify the alleles that can significantly reduce the hazard from $F$. verticillioides [16].

Resistance to FER is complex because it is characterized by a quantitative inheritance in which additive, dominant, epistatic, and genotype by environment interaction effects are important [18-21]. Based on biparental populations, Mapping studies have shown that resistance to FER is controlled by many genes with relatively small effects that vary in environments and populations [4, 22]. Although different maize inbred lines and hybrids own different genetic variation for resistance to FER, there is no evidence of maize materials with complete resistance to either FER or fumonisin contamination in maize [23-25]. It is very important to identify novel resistance genes against $F$. verticillioides in order to find a lasting solution to FER problems in maize production. Several studies have identified QTL associated with resistance to $F$. verticillioides and subsequent reduced fumonisin accumulation using cross-populations, such as F2, F2:3, RILs. Zhang et al. detected six and four QTL in a F2 population of 230 individuals in two environments, respectively, and two QTL were identified consistently in both environments [26]. Using a F2:3 population, Pérez-Brito et al. [21] detected 13 QTL for kernel resistance to FER, which displayed significant QTL $\times$ environment interactions, and Chen et al. [19] discovered a QTL for FER resistance affecting approximately $18 \%$ of the phenotypic variation and accounting for up to $35 \%$ of the phenotypic effect in near isogenic lines when in homozygosity. In two additional studies based on RIL populations, Ding et al. [20] detected two QTL on chromosome 3 (bin3.04), which were consistently identified across all environments, and found significant epistatic effects among QTL and interactions effects between mapped loci and environments, and $\mathrm{Li}$ et al. [27] detected a resistance QTL with $10.2 \%$ of the phenotypic variation, but no epistatic effects were detected. In addition, complexity of FER could be associated with grain moisture content (GM) and European corn borer (Ostrinia nubilalis) [28, 29].

Recently, to uncover genomic regions associated with reduced FER and fumonisin B1 (FB1) mycotoxin contamination and identify molecular markers to perform marker-assisted selection, Maschietto et al. [30] used an F2:3 population of 188 progenies developed by crossing CO441 (resistant) and CO354 (susceptible) genotypes and evaluated FER severity and FB1 contamination content, and detected 15 QTL for FER and 17 QTL for FB1 contamination. Eight QTL located on chromosomes 1, $2,3,6,7$, and 9 were in common between FER and FB1, making the selection of genotypes possible with resistance to FER and low fumonisin contamination [30]. Certainly, there are many other studies on resistance to FER based on linkage mapping. This approach is widely used because linkage mapping generates lower false positive results which make up the defect of few alleles in offspring populations [31-33]. However, no genes have been isolated by map-based cloning to date, and few stable QTL have been verified for molecular breeding.

GWAS has shown enormous potential for detecting QTL with high resolution in diverse germplasm [34]. A large number of recombinational events and tens of thousands of SNPs increase the accuracy and shorten the confidence interval of QTL mapping. Now many quantitative traits have been successfully studied by GWAS in maize [35]. In 2016, Chen and his colleagues presented 45 SNPs that were significantly related to FER resistance, each of which had relatively small additive effects on FER resistance and explained $1-4 \%$ of phenotypic variation [36]. In addition, works on GWAS for FER have been performed by many other research teams, 
such as [37-40], and so on. Compared to traditional linkage analysis, association mapping offers higher mapping resolution and eliminates the time and cost of developing synthetic mapping populations, which make up the defect of false positive [41, 42]. So combining GWAS and linkage mapping could play a great role in identifying casual loci $[43,44]$.

In this study, we reused linkage mapping to identify genomic regions associated with FER resistance in a biparental RIL population that was evaluated across four environments. Then, GWAS was performed based on the data collected from five environments to detect alleles associated with resistance to FER. Next, we validated four common genomic regions in NIL populations and analyzed the candidate genes in these regions. Last, we discussed the probable mechanism of resistance to FER and stable QTL for molecular breeding.

\section{Results}

\section{Phenotypic analysis}

First of all, we determined the best time of inoculation for ear rot. For determining the proper inoculation time, we evaluated the phenotype of six inoculation periods of the resistant materials, BT-1 and CML295, and susceptible N6 from the 5th to the 35th day after silking (Fig. S1). The resistant materials BT-1 and CML295 showed susceptibility from the 5 th to 10th day after silking, but were stable and resistant from the 15th to 35th day. The FER resistance of susceptible N6 became more and more resistant from the 5th to 35th day after silking. However, the most significant difference in resistance between N6 and BT-1 or CML295 was from the inoculation on 15th day after silking; thus, it was effortless to evaluate the materials inoculated at this time.
Descriptive statistics for FER resistance in the RIL and GWAS populations are presented in Table 1. There was a visible difference in resistance between parent lines BT-1 and N6, which had combined means 1.10 and 6.11, respectively (Fig. S2). The wide variations were also observed in each environment in the RIL and GWAS population, which ranged from 1 to 7 . The frequency of phenotypic value of the GWAS population for resistance followed an approximately normal distribution, but a skewed distribution in the RIL (Fig. S3). The genotypic variance $\left(\sigma_{\mathrm{g}}^{2}\right)$ and genotype-by-environment variance $\left(\sigma_{\text {ge }}^{2}\right)$ of resistance were significant in both populations. Heritability for resistance was 0.81 in the RIL population, 0.79 in the GWAS population. The high heritability indicated that much of the phenotypic variance was genetically controlled in the populations and suitable for QTL mapping.

\section{QTL mapping analysis}

A total of 10 QTL were identified for FER resistance (Table 2, Fig. S4), which were located on Chr. 1 (bin 1.02/03), Chr. 2 (bin 2.00/01), Chr. 3 (bin 3.01/02, 3.06/ 07), Chr. 4 (bin 4.05, 4.05/06, 4.08), Chr. 5 (bin 5.00, 5.03/04), and Chr. 10 (bin 10.6/07). The increasing resistance effect of eight QTL originated from the resistant parent BT-1, whereas only two QTL from the susceptible parent N6. Among these QTL, three QTL were located on chromosome 4 (bin 4.05/08) and the one WQ6 (bin 4.05/06) between markers mmc0371 and A007339 had the largest resistance effect for Fusarium ear rot, which could explain more than $9.3 \%$ of the phenotypic variation. Then the QTL, on bin 3.06/07 had the second largest resistance effect explaining about $4.5 \%$. These 10 QTL showed both additive effects (A) and additive by environment effects (AbyE), but additive effects

Table 1 Descriptive statistics of FER resistance for the RIL and GWAS populations in different environments

\begin{tabular}{|c|c|c|c|c|c|c|c|c|c|c|c|}
\hline \multirow[t]{2}{*}{ Population } & \multirow[t]{2}{*}{ Environment } & \multirow{2}{*}{$\begin{array}{l}\text { BT-1 } \\
\text { Mean }\end{array}$} & \multirow{2}{*}{\multicolumn{2}{|c|}{$\begin{array}{l}\text { N6 } \\
\text { Mean }\end{array}$}} & \multirow[t]{2}{*}{ Range } & \multirow[t]{2}{*}{ CV } & \multirow[t]{2}{*}{ Skewness } & \multirow[t]{2}{*}{ Kurtosis } & \multirow[t]{2}{*}{$\sigma_{g}^{2}$} & \multirow[t]{2}{*}{$\sigma_{g e}^{2}$} & \multirow[t]{2}{*}{$H^{2}$} \\
\hline & & & & & & & & & & & \\
\hline \multirow[t]{5}{*}{ RIL } & $2007 Z Z$ & $1.02 \pm 0.10$ & $6.30 \pm 0.04$ & $1.99 \pm 0.93$ & $1-6$ & 0.46 & 1.84 & 5.10 & $0.83^{* *}$ & - & 0.90 \\
\hline & $2008 Z Z$ & $1.26 \pm 0.14$ & $6.71 \pm 0.35$ & $2.06 \pm 0.90$ & $1-6$ & 0.44 & 1.06 & 2.20 & $0.76^{* *}$ & - & 0.88 \\
\hline & 2015WX & $1.10 \pm 0.22$ & $5.40 \pm 0.18$ & $2.23 \pm 0.92$ & $1-6$ & 0.41 & 0.88 & 0.90 & $0.73^{* *}$ & - & 0.75 \\
\hline & $2016 \times C$ & $1.30 \pm 0.19$ & $6.28 \pm 0.32$ & $2.06 \pm 1.26$ & $1-7$ & 0.61 & 1.88 & 4.28 & $1.41^{* *}$ & - & 0.73 \\
\hline & Combined & $1.10 \pm 0.17$ & $6.11 \pm 0.20$ & $2.13 \pm 0.75$ & $1-6$ & 0.39 & 1.49 & 3.99 & $0.60^{* *}$ & $0.34^{* *}$ & 0.81 \\
\hline \multirow[t]{6}{*}{ GWAS } & $2014 Z Z$ & - & - & $2.87 \pm 1.05$ & $1-7$ & 0.41 & 1.10 & 2.27 & $0.83^{* *}$ & - & 0.65 \\
\hline & $2015 Z Z$ & - & - & $3.00 \pm 0.78$ & $1-5$ & 0.25 & 0.44 & 0.27 & $0.39^{* *}$ & - & 0.65 \\
\hline & 2015WX & - & - & $2.81 \pm 1.03$ & $1-6$ & 0.40 & 0.50 & -0.11 & $0.82^{*}$ & - & 0.77 \\
\hline & $2016 Z Z$ & - & - & $2.25 \pm 1.14$ & $1-6$ & 0.55 & 0.97 & 0.26 & $1.08^{* *}$ & - & 0.70 \\
\hline & 2016 XC & - & - & $2.28 \pm 1.17$ & $1-7$ & 0.57 & 1.48 & 2.77 & $1.04^{* *}$ & - & 0.68 \\
\hline & Combined & - & - & $2.75 \pm 1.32$ & $1-5$ & 0.30 & 0.84 & 0.73 & $0.47^{* *}$ & $0.33^{* *}$ & 0.79 \\
\hline
\end{tabular}


Table 2 Quantitative trait loci (QTL) for FER resistance identified in the RIL population using the ICIM-ADD method under MET

\begin{tabular}{llllllll}
\hline QTL & Chromosome bin & Flanking markers & LOD $^{\mathrm{a}}$ & Add $^{\mathrm{b}}$ & PVE $^{\mathrm{C}}$ & PVE1 $^{\mathrm{d}}$ & PVE2 $^{\mathrm{e}}$ \\
\hline WQ1 & $1.02 / 1.03$ & bnlg1007-umc1403 & 2.9194 & 0.0992 & 1.7159 & 1.6136 & 0.1023 \\
WQ2 & $2.00 / 2.01$ & umc1419-phi96100 & 5.3504 & -0.1329 & 3.0405 & 2.9365 & 0.1041 \\
WQ3 & $3.01 / 3.02$ & umc2256-bnlg1144 & 3.3221 & -0.1024 & 1.8653 & 1.745 & 0.1203 \\
WQ4 & $3.06 / 3.07$ & bnlg197-umc1399 & 8.8928 & -0.1633 & 4.5355 & 4.367 & 0.1685 \\
WQ5 & 4.05 & bn34-indel-17 & 5.5677 & -0.085 & 2.7758 & 1.1562 & 1.6196 \\
WQ6 & $4.05 / 4.06$ & mmc0371-A007339 & 14.8914 & -0.2102 & 9.3098 & 7.127 & 2.1828 \\
WQ7 & 4.08 & dupssr28-bnlg2162 & 2.9395 & -0.0855 & 1.5863 & 1.2133 \\
WQ8 & 5.00 & umc1240-umc1097 & 2.93 & 0.0782 & 1.6397 & 1.0093 & 0.373 \\
WQ9 & $5.03 / 5.04$ & umc2298-umc1563 & 4.2737 & -0.1193 & 2.4109 & 2.3597 & 0.0512 \\
WQ10 & $10.06 / 10.07$ & bnlg2190-umc1196 & 3.571 & -0.0987 & 1.7937 & 1.6105 & 0.1831
\end{tabular}

${ }^{a}$ Log-likelihood value was calculated by the inclusive composite interval mapping of additive gene from multi-environmental trials method

${ }^{b}$ Positive value indicates the resistant gene contributed by parents N6. Negative value indicates the resistance gene from BT-1

c Phenotypic variation explained by QTL

${ }^{d}$ Explained phenotypic variation from additive effect

e Phenotypic variation explained by interaction effect between additive gene and environment

explained $25.1 \%$ of the phenotypic variation, whereas interaction effects explained only $5.5 \%$.

To determine the epistatic effect, epistatic QTL mapping was performed. A total of three pairs of QTL interactions were detected by the ICIM-EPI method at an LOD value of 7 , which explained 3.2, 2.4, and $2.4 \%$ of the phenotypic variation (Table S1, Fig. S5). The epistatic effect between QTL with flanking markers umc2256 and bnlg1144 and QTL with umc1791 and IDP4548 had the largest effect, and explained 3.2\%. Although each QTL had the negative additive effect, the interaction effect showed a positive effect, which revolved the complexity of the resistance to FER.

\section{GWAS for FER}

Single marker-based GWAS was performed using a mixed linear model (MLM) incorporating both the population structure (first three $\mathrm{PCs}$ ) and $\mathrm{K}$ into the model. A total of 18 SNPs were significantly associated with FER resistance with $p \leq 1.0 \times 10^{-4}$ (Table 3, Fig. 1). These SNPs explaining $5.6-10.2 \%$ of phenotypic variation was distributed on five chromosomes, and the number of SNPs per chromosome ranged from 1 on chromosome 3 to 6 on chromosomes 4 . The most significant SNP was located on chromosome 7 (S7_153, $838,246)$ with the lowest $P$ value $\left(3.38 \times 10^{-6}\right)$ and it explained $10.2 \%$ of the phenotypic variation. The second SNP with the lowest $P$ value was located on chromosome 4 and explained $6.8 \%$ of the phenotypic variation. Detailed information of 18 SNPs significantly associated with FER resistance is provided in Table 3. The QQ Plot showed that the observed $P$ value was in agreement with the expected $P$ value, whereas the observed $P$ value was lower than the expected $\mathrm{P}$ value at a threshold greater than three (Fig. S6). As a result, FER may not be explained by a major gene. Some loci with lower significance may not have been detected, but this should not have affected the identification of loci significantly associated with FER resistance. Based on the physical position of the significant SNPs in the B73 version 2 reference genome, these significant SNPs were associated with 11 candidate genes, some of which were directly involved in resistance according to gene annotation, GRMZM2G150179, for example.

Gene Ontology (GO) annotation was carried out on 11 candidate genes identified by GWAS. The process of growth, stress response, and cell formation was significantly enriched. These processes feel into four main categories, including seven associated candidate genes. The first was the cytoskeleton process, including cytoskeleton and cellular component organization, and involved candidate genes GRMZM2G449160 and GRMZM2G463471. The second was the process of protein binding, which involved the most genes, including GRMZM2G107686, GRMZM2G086072, GRMZM2G463471, GRMZM2G134980, and GRMZM5G818643, which indicated the significance in FER in posttranslational regulation. The third category was the process of regulation of cellular processes, and contained GRMZM2G107686, GRMZM2G086072, and GRMZM2G449160. The last category was the process of stress response, involving GRMZM2G059381 and GRMZM2G134980.

\section{Conjoint analysis for FER resistance}

Ten QTL identified through linkage mapping and 18 significant single SNPs detected by GWAS were integrated to analyze the resistance, and four consistent loci were found (Table 4), located on bin3.01/3.02 (WQ4), bin4.05/4.06 (WQ5, WQ6), bin4.08 (WQ7), and bin5.00 (WQ8). These SNPs were further studied in the 
Table 3 The significant single nucleotide polymorphisms (SNPs) and their candidate genes associated with FER resistance identified in this study

\begin{tabular}{|c|c|c|c|c|c|c|c|}
\hline SNP & Chromosome & Pos & $\mathrm{P}$ & $R^{2}$ & location & Candidate Gene & Annotation \\
\hline S1_9,398,408 & 1 & $9,398,408$ & $\begin{array}{l}5.72 \mathrm{E}- \\
05\end{array}$ & 0.057312 & intragenic & GRMZM2G107686 & Xylem serine proteinase 1 \\
\hline S1_11,487,039 & 1 & $11,487,039$ & $\begin{array}{l}2.93 \mathrm{E}- \\
05\end{array}$ & 0.070112 & intragenic & GRMZM2G086072 & Transcription factor-like protein DPB \\
\hline $\begin{array}{l}\text { S1_232,529, } \\
882\end{array}$ & 1 & $\begin{array}{l}232,529 \\
882\end{array}$ & $\begin{array}{l}8.36 \mathrm{E}- \\
05\end{array}$ & 0.060307 & intragenic & GRMZM2G150179 & Putative disease resistance RPP13-like protein 1 \\
\hline S3_1,591,322 & 3 & $1,591,322$ & $\begin{array}{l}8.16 \mathrm{E}- \\
05\end{array}$ & 0.056117 & promoter & GRMZM2G449160 & $\begin{array}{l}\text { Glutaredoxin domain-containing cysteine-rich protein } \\
1\end{array}$ \\
\hline $\begin{array}{l}\text { S4_153,270, } \\
141\end{array}$ & 4 & $\begin{array}{l}153,270 \\
141\end{array}$ & $\begin{array}{l}6.37 \mathrm{E}- \\
05\end{array}$ & 0.058369 & intragenic & GRMZM2G463471 & Actin-depolymerizing factor \\
\hline $\begin{array}{l}\text { S4_153,270, } \\
174\end{array}$ & 4 & $\begin{array}{l}153,270 \\
174\end{array}$ & $\begin{array}{l}4.05 \mathrm{E}- \\
05\end{array}$ & 0.061957 & & & \\
\hline $\begin{array}{l}\text { S4_178,501, } \\
587\end{array}$ & 4 & $\begin{array}{l}178,501 \\
587\end{array}$ & $\begin{array}{l}9.53 \mathrm{E}- \\
05\end{array}$ & 0.056872 & promoter & GRMZM2G356046 & Putative mannan endo-1,4-beta-mannosidase 9 \\
\hline $\begin{array}{l}\text { S4_187,594, } \\
182\end{array}$ & 4 & $\begin{array}{l}187,594 \\
182\end{array}$ & $\begin{array}{l}6.24 \mathrm{E}- \\
05\end{array}$ & 0.070366 & intragenic & GRMZM2G059381 & chain acyl-CoA synthetase 7, peroxisomal \\
\hline $\begin{array}{l}\text { S4_202,889, } \\
727\end{array}$ & 4 & $\begin{array}{l}202,889 \\
727\end{array}$ & $\begin{array}{l}1.86 \mathrm{E}- \\
05\end{array}$ & 0.068033 & - & - & - \\
\hline $\begin{array}{l}\text { S4_205,928, } \\
061\end{array}$ & 4 & $\begin{array}{l}205,928 \\
061\end{array}$ & $\begin{array}{l}4.64 \mathrm{E}- \\
05\end{array}$ & 0.062262 & - & - & - \\
\hline S5_6,358,869 & 5 & $6,358,869$ & $\begin{array}{l}3.27 \mathrm{E}- \\
05\end{array}$ & 0.063575 & promoter & GRMZM2G176042 & Protein FAM135A \\
\hline S5_16,324,316 & 5 & $16,324,316$ & $\begin{array}{l}9.26 \mathrm{E}- \\
05\end{array}$ & 0.061203 & intragenic & GRMZM2G134980 & protein DnaJ \\
\hline S5_16,324,318 & 5 & $16,324,318$ & $\begin{array}{l}9.26 \mathrm{E}- \\
05\end{array}$ & 0.061203 & & & \\
\hline $\begin{array}{l}\text { S7_129,966, } \\
178\end{array}$ & 7 & $\begin{array}{l}129,966 \\
178\end{array}$ & $\begin{array}{l}8.89 \mathrm{E}- \\
05\end{array}$ & 0.056173 & promoter & GRMZM5G818643 & Transcription factor bHLH49 \\
\hline $\begin{array}{l}\text { S7_129,966, } \\
180\end{array}$ & 7 & $\begin{array}{l}129,966 \\
180\end{array}$ & $\begin{array}{l}8.89 \mathrm{E}- \\
05\end{array}$ & 0.056173 & & & \\
\hline $\begin{array}{l}\text { S7_129,966, } \\
182\end{array}$ & 7 & $\begin{array}{l}129,966 \\
182\end{array}$ & $\begin{array}{l}8.89 \mathrm{E}- \\
05\end{array}$ & 0.056173 & & & \\
\hline $\begin{array}{l}\text { S7_129,966, } \\
183\end{array}$ & 7 & $\begin{array}{l}129,966 \\
183\end{array}$ & $\begin{array}{l}8.89 \mathrm{E}- \\
05\end{array}$ & 0.056173 & & & \\
\hline $\begin{array}{l}\text { S7_153,838, } \\
246\end{array}$ & 7 & $\begin{array}{l}153,838 \\
246\end{array}$ & $\begin{array}{l}3.38 \mathrm{E}- \\
06\end{array}$ & 0.101554 & promoter & GRMZM2G488098 & Unknown \\
\hline
\end{tabular}

following experiment. From the conjoint analysis, identification of consistent loci suggested that there were resistance loci for FER with stable effects at different genetic backgrounds and environmental conditions.

\section{QTL verification}

To fine map the QTL (WQ5, WQ6, and WQ7) on chromosome 4, a NIL population with the genetic background of susceptible parent N6 was developed using a backcross and marker assistance selection with flanking markers. The percentage of infected kernels (PIK) was brought into the phenotype evaluation. The lines N-44 and N-54 with positive homozygous alleles (WQ5, WQ6, and WQ7) from the resistant parent BT-1 showed a lower PIK compared with N-55 and N6, and N-55 with only WQ5 and WQ6 was more resistant than parent N6, but more susceptible than lines N-44 and N-54, regardless of Zhengzhou and Xuchang. This indicated that WQ7 could decrease approximately 8 and 6 PIK. WQ5 and WQ6 together improved approximately 7 and $8 \%$ in resistance compared with N6 in Zhengzhou and Xuchang, respectively (Table 5). The analysis of variance also showed the same result, which indicated that these three QTL could increase resistance to FER. The detailed genotypes and phenotypes of the three NILs can been found in the supplementary materials (Table S2, Fig. 2).

A segregation population was constructed for WQ3 by a backcross between the NIL, CP-1 with the target the fragment linked with umc2101 and umc2256, and 


\section{Manhattan Plot}

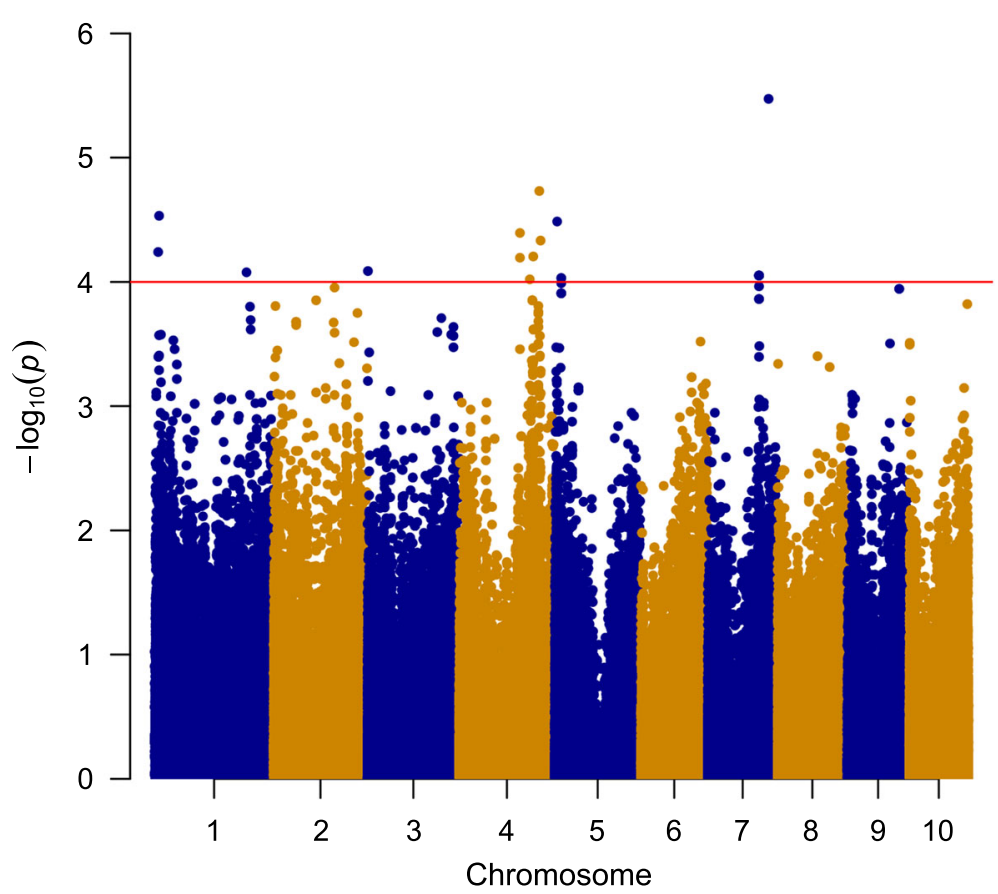

Fig. 1 Manhattan plots of GWAS for the F. verticillioides ear rot resistance in maize

recurrent parent N6. Finally, WQ3 was verified by a family with a total of 58 plants in 2017 (Table S3).

Furthermore, the GWAS also showed a total of four significant SNPs with $p<1 \times 10^{-4}$ in these verified QTL and represented three candidate genes: GRMZM2G449160 for WQ3, GRMZM2G463471 for WQ5 and WQ6, and GRMZM2G059381 for WQ7 (Table 4).

\section{Discussion}

\section{QTL analysis and GWAS for FER resistance}

QTL analysis is a well-established and widely-used tool for dissecting the genetic basis of complex traits in plants [45]. Many QTL associated with important agronomic traits have been mapped but only a few causal genes were cloned in cereals [46, 47]. Similarly, to date, many QTL have been mapped, but no causal genes have been cloned underlying QTL for FER resistance controlled by many minor-effect QTL that play a great role in maize [48]. These indicate that the positional cloning of minor-effect QTL is still difficult because of their low heritability. Compared to traditional linkage-based analyses, GWAS offers higher mapping effects containing mapping resolution and a greater number of loci, because of many polymorphic SNPs, and eliminates the time and cost associated with developing synthetic mapping populations $[41,42]$. However, GWAS easily generates false positive results because of the population structure. Thus, combining GWAS and linkage mapping could exploit the complementary strengths of both approaches to identify casual loci or genes [43, 44].

To decrease the loss from FER and explore the genetic mechanism, we begin to study resistance to FER more than a decade years ago. Today, we have formed a series of relatively perfect inoculating systems and phenotypic identification methods [49], and have achieved some degree of success $[19,27,36,50-52]$. In this study, 10 QTL and 18 SNPs $\left(P<1 \times 10^{-4}\right)$ were detected on the

Table 4 The consistent loci from linkage mapping and GWAS

\begin{tabular}{llllll}
\hline QTL & Bin & flanking marker & SNP & position & candidate gene \\
\hline WQ3 & $3.01 / 3.02$ & umc2256-bnlg1144 & S3_1,591,322 & $1,591,322$ & GRMZM2G449160 \\
WQ5 & 4.05 & bn34-indel-17 & S4_153,270,141 & $153,270,141$ & GRMZM2G463471 \\
WQ6 & $4.05 / 4.06$ & mmc0371-A007339 & S4_153,270,174 & $153,270,174$ & \\
WQ7 & 4.08 & dupssr28-bnlg2162 & S4_187,594,182 & $187,594,182$ & GRMZM2G059381 \\
WQ8 & 5.00 & umc1240-umc1097 & S5_6,358,869 & $6,358,869$ & GRMZM2G176042 \\
\hline
\end{tabular}


Table 5 The genotype and phenotype of NILs in two environments

\begin{tabular}{lllllllll}
\hline NILs & WQ5 & WQ6 & WQ7 & \multicolumn{4}{l}{ PIK (\%) and significance } \\
\cline { 5 - 8 } & & & & Zhengzhou & & Xuchang & \\
\hline $\mathrm{N}-44$ & + & + & + & $5.11 \pm 0.04$ & $\mathrm{c}$ & $3.48 \pm 0.03$ & $\mathrm{c}$ \\
$\mathrm{N}-54$ & + & + & + & $4.15 \pm 0.03$ & $\mathrm{c}$ & $2.94 \pm 0.02$ & $\mathrm{c}$ \\
$\mathrm{N}-55$ & + & + & - & $12.60 \pm 0.06$ & $\mathrm{~b}$ & $8.03 \pm 0.04$ & $\mathrm{~b}$ \\
$\mathrm{~N} 6$ & - & - & - & $19.10 \pm 0.12$ & a & $16.62 \pm 0.07$ & a \\
\hline
\end{tabular}

Note:+ represents for fragment from BT-1; - stands for fragment from N6; $a, b$, $c$ showed the results of Multiple measures ANOVA

whole genome. Among them, four significant SNPs were located in four QTL, which represented three candidate genes, GRMZM2G449160, GRMZM2G463471, and GRMZM2G059381. GRMZM2G449160 is a member of glutaredoxins (GRXs), which belongs to the antioxidants involved in cellular stress responses. Proteomic analysis found that homologous OsGRX20 increased by 2.7-fold after infection by bacterial blight in rice [53]. GRMZM2G059381 belongs to the AMP-binding protein and the homologous $O s B I A B P 1$ is involved in the regulation of the defense response through salicylic acid (SA) and/or jasmonic acid (JA) / ethylene (ET) signaling pathways [54]. GRMZM2G463471 is a member of the actin-depolymerizing factors (ADFs), whose primarily function is to regulate the severing and depolymerization of actin filaments. However, in recent years, the activity of ADFs proteins has been linked to a variety of cellular processes, including those associated with responses to stress. Zhang et al. [55] found a member of ADFs, e.g., TaADF4, from wheat, was required for resistance to the stripe rust pathogen Puccinia striiformis f sp. Tritici. These results indicate that the three candidate genes in this study may be associated with FER resistance in maize, which will be focused on in the following study.

\section{Phenotypic evaluation for FER resistance}

An accurate phenotype is the key to the study of FER. The acquisition of the phenotype was influenced by the inoculation method, date, and the inoculation dose. At present, there are three common inoculation methods used for the study of FER resistance, namely the silk channel inoculation method [56, 57], silk sprayed with inoculum method [4], and the sponge and nail punch method [58]. Among them, the last method is widely used because of easy control of the inoculation dose.

In the long-term study of FER, we explored and optimized the nail punch method [49]. The key to this approach is the operation timing of inoculation. This method is most suitable for inoculation in the milk ripening period, the 15th day after silking, because earlier or later inoculation can not accurately reflect the resistance of the materials. The most significant difference in resistance between susceptible inbred line N6 and resistant inbred line BT-1 or CML295 was from the inoculation on 15th day after silking; thus, it was effortless to evaluate the materials inoculated at this time. To assess the resistance of polymorphic GWAS population, it was divided into two parts according to the date after silking and planted at two different times to ensure the same time of inoculation.

\section{Stable QTL for Fusarium resistance in different tissues and studies}

For more than 10 years, our group studied Fusarium resistance in different maize tissues [19, 27, 36, 50-52]. We confirmed that the resistance loci and mechanism of different tissues were different. In the GWAS population, we found some lines showed different resistance between different tissues, for example some lines had high FER resistance with weak Fusarium cob rot resistance (FCR) and Fusarium seed rot resistance (FSR). Therefore, we compared the QTL identified for Fusarium resistance in ear, cob (FCR), and seed (FSR) (Fig. 3a). These studies used the same resistance parent line and similar susceptible lines, but had different results [50, 52]. Some QTL were independent, for example, the QTL located on bin $3.01 / 02$, bin 5.00 , and bin $10.06 / 07$ were
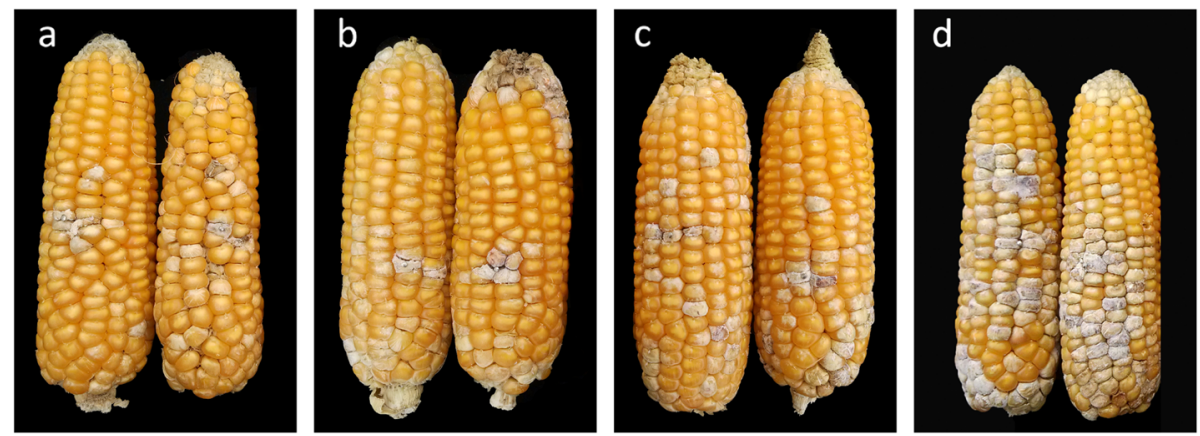

Fig. 2 Phenotypic variation in FER severity at harvest among the NILs in artificially inoculated ears with F. verticillioides. N-44 is represented by the two ears on the left (a), N-54 (b), N-55 (c) in the middle, and N6 on the right (d) 


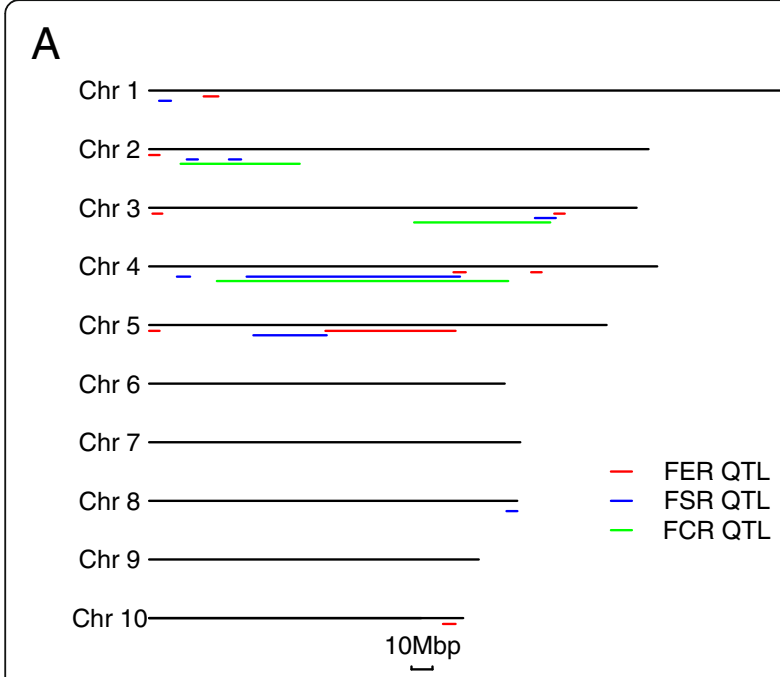

B

Fig. 3 QTL and SNPs for Fusarium resistance in different tissues and studies. a) Comparison of QTL for Fusarium rot resistance detected by different tissues. b) Comparison of QTL and SNPs for Fusarium ear rot resistance detected by previous reports. Colored lines represent different QTL or SNPs in different studies

specific for FER. However, there were still some QTL that appeared conservative; for example, QTL in bin 3.06/3.07 and 4.05/4.06 were identified in FER, FCR, and FSR. These conservative QTL were not identified for $\mathrm{Fu}$ sarium seeding rot, which may cause by different resistant mechanism or different research populations [59]. The candidate genes identified by GWAS were different between these three traits, as well $[50,52,60]$. It is worth mentioning that many candidate genes for FCR were involved in cell and tissue development, whereas none of this kind of gene was identified in FER. These results suggested that the resistance against Fusarium in maize is a complex trait, which requires continued research to resolve this important production problem.

In our previous study [27], four QTL located in bin3.01/4.06/5.01/6.04 were detected using composite interval mapping method across two environments (2007ZZ and 2008ZZ). Among these QTL, two QTL in bin3.01/5.01 were also detected in this study, but the QTL in bin4.06 in the previous study was not detected; rather bin4.05/4.06 and bin4.08 in this study were verified by NILs. Moreover, no significant loci were detected on chromosome 6 in the RIL population and GWAS population in this analysis.

Previous studies $[19,30,36,37,61,62]$ together with the present study were compared, which showed that loci for FER resistance are widely distributed, indicating FER resistance is a complex trait controlled by many minor QTL (Fig. 3b). The five common loci detected in RIL and GWAS populations were also identified by other researchers showing that these QTL were stable. These results also indicated that maybe it was effective to increase resistance according to selecting lines with a few stable QTL. Furthermore, the QTL verified by NILs on bin 3.06/07 and 4.05/06 will be the focus on our following study plan, because they were identified by different research and Fusarium resistance traits.

\section{Conclusions}

In this study, a RIL populations and one GWAS population were used to identify and map QTL for FER resistance. A total of 10 QTL for FER resistance were detected by QTL mapping and 18 SNPs were identified by GWAS at $P<1 \times 10^{-4}$. Four QTL of the five common loci in the RIL and GWAS were verified in NILs and three candidate genes may be associated with FER resistance. These results confirmed that FER resistance was strongly controlled by multiple genes with low effect and the QTL and candidate genes identified in this study could help to better understand the genetic basis and explore the mechanism of FER resistance. At the same time, it was feasible to select maize lines with higher $\mathrm{Fu}$ sarium resistance because of the two stable QTL in different tissues and studies.

\section{Methods}

\section{Germplasm and experimental design}

A biparental population composed of 250 recombinant inbred lines (RILs) was constructed by a cross between inbred lines BT-1 and N6 (Fig. S2) by the single-seed descent method. The line BT-1 was reformed by tropical Asia material with highest resistance to FER, which was screened out of 90 inbred lines inoculated with Fusarium verticillioides [63], whereas the susceptible N6 was a Tangsipingtou line. The RIL population together with the two parents were grown in Zhengzhou $\left(34^{\circ} 52^{\prime} \mathrm{N}\right.$ 
$\left.113^{\circ} 37^{\prime} \mathrm{E}\right)$ in 2007 and 2008 (2007ZZ, 2008ZZ), Wenxian $\left(34^{\circ} 57^{\prime} \mathrm{N} 113^{\circ} 2^{\prime} \mathrm{E}\right)$ in 2015 (2015WX), and Xuchang $\left(34^{\circ} 3^{\prime} \mathrm{N} 113^{\circ} 41^{\prime} \mathrm{E}\right)$ in $2016(2016 \mathrm{XC})$. These three areas have a temperate continental climate, with adequate rainfall and enough light-temperature resource in the growing period of maize. NILs were developed by crossing a recipient line $\mathrm{N} 6$ with the donor line BT-1 through five cycles of advanced backcrosses. These NILs were evaluated in 2016 and 2017.

The GWAS population consisting of 265 maize inbred lines from the heterotic populations Tangsipingtou, Reid, Lancaster, P group, and some tropical lines from the International Maize and Wheat Improve Center (CIMMYT), was evaluated in Zhengzhou in 2014, 2015, and 2016 (2014ZZ, 2015ZZ, and 2016ZZ) and Wenxian in 2015 (2015WX) and Xuchang in 2016 (2016XC).

All the populations above were laid out in a randomized complete block design with two replications in each environment. Sixteen plants were planted in $4 \mathrm{~m}$ row plots with $0.67 \mathrm{~m}$ row spacing. Importantly, pesticide was artificially sprayed at the ten-leaf stage to control corn borers. Some other field management was performed according to the standard agronomic practices in each location.

\section{Inoculation and FER evaluation}

A single-spore isolate of $F$. verticillioides was reproduced artificially on sterile mature maize kernels, incubated for $7 \mathrm{~d}$ at $28^{\circ} \mathrm{C}$. Then, the spores were harvested, and the concentration was estimated using a hemocytometer and adjusted to $1 \times 10^{6}$ spores $\mathrm{ml}^{-1}$ in sterile distilled water with $0.2 \mu \mathrm{l} / \mathrm{ml}$ Tween 80 surfactant. The top ear of each plant in each row was inoculated for $2 \mathrm{ml}$ spore suspension on the fifteenth day after silking using the sponge and the nail punch method [58] along with the portable inoculating tool assembled by ourselves.

Resistance to FER was assessed by disease severity according to Reid et al. [64] using a rating scale from 1 to 7 [64]. Ten ears of each line in a row were selected for phenotypic evaluation and the final data for each replication was the average value. The average rating scale from the two replications represented the final value in each environment.

\section{Phenotypic data analysis}

The analysis of variance (ANOVA) of phenotype data was carried out using the multifunctional IciMapping version 4.2 [65]. Best linear unbiased predictions (BLUPs) of the combined resistance to FER for each line in Linkage analysis and GWAS were calculated by using a mixed linear model (lmer) in the $\mathrm{R}$ version 3.6.0 with the $\mathrm{R}$ stats package [66], in which used replication, environments (year-location combinations), and entries were considered random effects. The BLUP value of each line was used for GWAS analysis.

\section{Linkage mapping}

In our previous study, we constructed a linkage map of the RIL population $(\mathrm{BT} \times \mathrm{N} 6)$, which contained 207 polymorphic SSR markers and had a length of 1820.8 cM with an average $11.7 \mathrm{cM}$ distance [27]. In this study, we reconstructed a linkage map with 222 polymorphic markers using the IciMapping version 4.2, which had a total length of $1890.7 \mathrm{cM}$ and an average genetic distance of $8.5 \mathrm{cM}$ between markers.

To understand the QTL by environment interaction effects, the mapping strategy of MET (mapping of additive and digenic epistasis genes from multienvironmental trials) was performed in the IciMapping software. Two methods were used in QTL mapping, i.e., (i) ICIM-ADD: Inclusive Composite Interval Mapping of additive QTL (ii) ICIM-EPI: Inclusive Composite Interval Mapping of digenic epistatic QTL. The threshold value of LOD was 2.5 for ICIM-ADD and 7 for ICIMEPI.

\section{GWAS and candidate gene annotation}

Through the genotyping-by-sequencing (GBS) method conducted in Cornell University, a total of 955,650 SNPs were identified in the GWAS population $[67,68]$, and the SNP flanking sequence and position information were available on the "panzea" website (http://cbsusrv04. tc.cornell.edu/users/panzea/download.aspx?filegroupid= 4). The filtered parameters of SNPs, linkage disequilibrium (LD) between each pair of SNPs, the principal component analysis (PCA), Kinship matrix and population structure analysis were performed according to our previous study [69].

Candidate gene information was obtained from the MaizeGDB (http://www.maizegdb.org/) genome browser based on the physical position of significant SNPs in B73 RefGen_v2.

\section{Supplementary information}

Supplementary information accompanies this paper at https://doi.org/10. 1186/s12864-020-6733-7.

Additional file 1:

Additional file 2:

\section{Abbreviations}

FER: Fusarium ear rot; RIL: Recombinant inbred lines; QTL: Quantitative trait loci; SNPs: Single nucleotide polymorphisms; GWAS: Genome-wide association study; NILs: Near-isogenic lines; ADFs: Actin-depolymerizing factors; FCR: Fusarium cob rot; FSR: Fusarium seed rot; GO: Gene Ontology; PIK: Percentage of infected kernels 


\section{Acknowledgements}

This work was financially supported by the International (Regional) Joint Research Project of the National Natural Science Foundation of China (Grant No. 31761143009) and the Co-construction State Key Laboratory of Wheat and Crop Science of China.

\section{Authors' contributions}

$J W, Y W$, and ZZ designed the experiments and wrote the manuscript. YW, $C D, J D, H L, Y H, R W, X S, J L, X D, W S$, and WC performed the QTL identified experiments. YW, CD, ZZ, CM, and XL performed the GWAS experiments and the NIL verify experiments. YW, ZZ, and JC analyzed the data. XZ and JC contributed GWAS population and analysis tools. ZZ analyzed candidate genes and prepared figures. All these authors have read and approved this manuscript.

\section{Funding}

This study was supported by the International (Regional) Joint Research Project of the National Natural Science Foundation of China (Grant No. 31761143009) and the Co-construction State Key Laboratory of Wheat and Crop Science of China.

\section{Availability of data and materials}

The datasets used and/or analysed during the current study are available from the corresponding author on reasonable request.

\section{Ethics approval and consent to participate}

Not applicable.

\section{Consent for publication}

Not applicable.

\section{Competing interests}

The authors declare that there are no conflicts of interest.

\section{Author details}

${ }^{1}$ College of Agronomy, Henan Agricultural University, Zhengzhou 450002, China. ${ }^{2}$ Global Maize Program, International Maize and Wheat Improvement Center (CIMMYT), Apdo 6-641, 06600 Mexico, DF, Mexico. ${ }^{3}$ College of Life Sciences, Synergetic Innovation Center of Henan Grain Crops and National Key Laboratory of Wheat and Maize Crop Science, Henan Agricultural University, Zhengzhou 450002, China.

\section{Received: 13 August 2019 Accepted: 14 April 2020}

\section{Published online: 12 May 2020}

\section{References}

1. Munkvold GP, Desjardins AE. Fumonisins in maize: can we reduce their occurrence. Plant Dis. 1997:81:556-65.

2. Missmer S, Suarez L, Felkner M. Exposure to fumonisins and the occurrence of neural tube defects along the Texas-Mexico border. Environ Health Perspect. 2006;114:237-41.

3. Kebebe AZ, Reid LM, Zhu X, Wu J, Woldemariam T, Voloaca C, Xiang K. Relationship between kernel drydown rate and resistance to Gibberella ear rot in maize. Euphytica. 2014;201:79-88.

4. Mesterházy Á, Lemmens M, Reid LM. Breeding for resistance to ear rots caused by Fusarium spp. in maize - a review. Plant Breed. 2012;131:1-19.

5. Seifert KA, Aoki T, Baayen RP, Brayford D, Burgess LW, Chulze S, Gams W, Geiser D, Gruyter JD, Leslie JF, Logrieco A, Marasas WFO, Nirenberg HI, Donnell KO, Rheeder J, Samuels GJ, Summerell B, Thrane U, Waalwijk C. The name Fusarium moniliforme should no longer be used. Mycol Res. 2003;107: 643-4.

6. Ridenour JB, Bluhm BH. The novel fungal-specific gene FUG1 has a role in pathogenicity and fumonisin biosynthesis in Fusarium verticillioides. Mol Plant Pathol. 2017:18(4):513-28.

7. Duan C, Qin Z, Yang Z, et al. Identification of Pathogenic Fusarium spp. Causing Maize Ear Rot and Potential Mycotoxin Production in China. Toxins (Basel). 2016;8(6):186.

8. Fu M, Li R, Guo C, Pang M, Liu Y, Dong J. Natural incidence of Fusarium species and fumonisins B1 and B2 associated with maize kernels from nine provinces in China in 2012. Food Addit Contam Part A Chem Anal Control Expo Risk Assess. 2015;32(4):503-11.
9. Zhang XF, Zou CJ, Cui LN, Xiao LI, Yang XR, Luo HH. Identification of pathogen causing maize ear rot and inoculation technique in Southwest China. Southwest China Journal of Agricultural Sciences. 2012;25:2078-82.

10. Munkvold GP. Epidemiology of Fusarium diseases and their mycotoxins in maize ears. Eur J Plant Pathol. 2003;109:705-13.

11. Logrieco A, Bottalico A, Mulè G, Moretti A, Perrone G, Mulé G, Moretti A, Perrone $G$. Epidemiology of toxigenic fungi and their associated mycotoxins for some Mediterranean crops. Eur J Plant Pathol. 2003;109:645-67.

12. Santiago R, Cao A, Butrón A. Genetic factors involved in fumonisin accumulation in maize kernels and their implications in maize agronomic management and breeding. Toxins. 2015;7:3267-96.

13. Irma MR, De YMJ, Silva-Rojas HV, Gabino GDLS, Guzmán-De-Peña DA. Biodiversity of Fusarium species in Mexico associated with ear rot in maize, and their identification using a phylogenetic approach. Mycopathologia. 2007;163(1):31-9.

14. Covarelli L, Stifano S, Beccari G, Raggi L, Lattanzio VM, Albertini E. Characterization of Fusarium verticillioides strains isolated from maize in Italy: Fumonisin production, pathogenicity and genetic variability. Food Microbiol. 2012;31:17-24.

15. Gelderblom WC, Jaskiewicz K, Marasas WF, Thiel PG, Horak RM, Vleggaar R, Kriek NP. Fumonisins-novel mycotoxins with cancer-promoting activity produced by Fusarium moniliforme. Appl Environ Microbiol. 1998;54:1806-11.

16. Mukanga M, Derera J, Tongoona P. Gene action and reciprocal effects for ear rot resistance in crosses derived from five tropical maize populations. Euphytica. 2010;174:293-301.

17. Robertson LA, Jines MP, Balint-Kurti P, Kleinschmidt CE, White DG, Payne G, Maragos CM, Molnár TL, Holland JB. QTL mapping for Fusarium ear rot and Fumonisin contamination resistance in two maize populations. Crop Sci. 2006:46:1734-44.

18. Boling MB, Grogan CO. Gent action affecting host resistance to Fusarium ear rot of maize. Crop Sci. 1965;4:305-7.

19. Chen J, Ding J, Li H, Li Z, Sun X, Li J, Wang R, Dai X, Dong H, Song W, Chen W, Xia Z, Wu J. Detection and verification of quantitative trait loci for resistance to Fusarium ear rot in maize. Mol Breed. 2012;30:1649-56.

20. Ding JQ, Wang XM, Subhash C, Yan JB, Li JS. QTL mapping of resistance to Fusarium ear rot using a ril population in maize. Mol Breed. 2008:22:395-403.

21. Pérez-Brito D, Jeffers D, González-de-León D, Khairallah M, CortésCruz M, Velázquez-Cardelas M, Azpíroz-Rivero S, Srinivasan G. QTL mapping of Fusarium moniliforme ear rot resistance in highland maize, Mexico. Agrociencia. 2001;35:181-96.

22. Lanubile A, Maschietto V, Borrelli VM, Stagnati L, Logrieco AF, Marocco A. Molecular basis of resistance to Fusarium ear rot in maize. Front Plant Sci. 2017;8:1774

23. Clements MJ, Maragos CM, Pataky JK, White DG. Sources of resistance to fumonisin accumulation in grain and Fusarium ear and kernel rot of corn. Phytopathology. 2004;94:251-60.

24. Clements M, Kleinschmidt C. Evaluation of inoculation techniques for Fusarium ear rot and fumonisin contamination of corn. Plant Dis. 2003;87:147-53.

25. Lanubile A, Pasini L, Lo Pinto M, Battilani P, Prandini A, Marocco A. Evaluation of broad spectrum sources of resistance to Fusarium verticillioides and advanced maize breeding lines. World Mycotoxin J. 2011;1:43-51.

26. Zhang F, Wan XQ, Pan GT. Molecular mapping of QTL for resistance to maize ear rot caused by Fusarium moniliforme. Acta Agron Sin. 2007:491-6.

27. Li ZM, Ding JQ, Wang RX, Chen JF, Sun XD, Chen W, Song WB, Dong HF, Dai XD, Xia ZL, Wu JY. A new QTL for resistance to Fusarium ear rot in maize. J Appl Genet. 2011;52:403-6.

28. Blandino M, Scarpino V, Vanara F, Sulyok M, Krska R, Reyneri A. Role of the European corn borer (Ostrinia nubilalis) on contamination of maize with 13 Fusarium mycotoxins. Food Addit Contam Part A Chem Anal Control Expo Risk Assess. 2015;32(4):533-43.

29. Xiang $\mathrm{K}$, Reid LM, Zhang ZM, Zhu XY, Pan GT. Characterization of correlation between grain moisture and ear rot resistance in maize by QTL metaanalysis. Euphytica. 2012;183(2):185-95.

30. Maschietto V, Colombi C, Pirona R, Pea G, Strozzi F, Marocco A, Rossini L, Lanubile A. QTL mapping and candidate genes for resistance to Fusarium ear rot and fumonisin contamination in maize. BMC Plant Biol. 2017;17:20.

31. Ding J, Zhang L, Chen J, Li X, Li Y, Cheng H, Huang R, Zhou B, Li Z, Wang J, Wu J. Genomic dissection of leaf angle in maize (Zea mays L.) using a fourway cross mapping population. PLoS One. 2015;10:e0141619.

32. Jiang $C$, Zeng ZB. Multiple trait analysis of genetic mapping for quantitative trait loci. Genetics. 1995;140(3):1111-27. 
33. Yang $Q$, Zhang $D, X u M . A$ sequential quantitative trait locus fine-mapping strategy using recombinant-derived progeny. J Integr Plant Biol. 2012;54: 228-37.

34. Buntjer JB, Sørensen AP, Peleman JD. Haplotype diversity: the link between statistical and biological association. Trends Plant Sci. 2005;10:466-71.

35. Xiao Y, Liu H, Wu L, Warburton M, Yan J. Genome-wide association studies in maize: praise and stargaze. Mol Plant. 2017;10:359.

36. Chen J, Shrestha R, Ding J, Zheng H, Mu C, Wu J, Mahuku G. Genome-wide association study and QTL mapping reveal genomic loci associated with Fusarium ear rot resistance in tropical maize germplasm. Genes Genom Genet. 2016;6:3803-15

37. Butron A, Santiago R, Cao A, Samayoa LF, Malvar RA. QTL for resistance to Fusarium ear rot in a multiparent advanced generation intercross (MAGIC) maize population. Plant Dis. 2019;103(5):897-904

38. Coan MMD, Senhorinho HJC, Pinto RJB, Scapim CA, Tessmann DJ, Paul WW, Warburton ML. Genome-wide association study of resistance to ear rot by, in a tropical field maize and popcorn core collection. Crop Sci. 2018;58(2): 564.

39. Zila CT, Ogut F, Romay MC, Gardner CA, Buckler ES, Holland JB. Genomewide association study of Fusarium ear rot disease in the U.S.A. maize inbred line collection. BMC Plant Biol. 2014;14(1):372.

40. Zila CT, Samayoa LF, Santiago R, Butrón A, Holland JB. A genome-wide association study reveals genes associated with Fusarium ear rot resistance in a maize core diversity panel. G3 (Bethesda). 2013;3(11):2095-104.

41. Flint-Garcia SA, Thuillet AC, Yu J, Pressoir G, Romero SM, Mitchell SE, Doebley J, Kresovich S, Goodman MM, Buckler ES. Maize association population: a high-resolution platform for quantitative trait locus dissection. Plant J. 2005:44:1054-64.

42. Yu J, Buckler EES, Mamo BE, Barber BL, Steffenson BJ. Genetic association mapping and genome organization of maize. Plant Biotechnology. 2006;17: 155-60.

43. Motte H, Vercauteren A, Depuydt S, Landschoot S, Geelen D, Werbrouck S, Goormachtig S, Vuylsteke M, Vereecke D. Combining linkage and association mapping identifies RECEPTOR-LIKE PROTEIN KINASE1 as an essential Arabidopsis shoot regeneration gene. Proc Natl Acad Sci U S A. 2014;111:8305-10

44. Pedergnana V, Syx L, Cobat A, Guergnon J, Brice P, Fermé C, Carde P, Hermine O, Le-Pendeven C, Amiel C, Taoufik Y, Alcais A, Theodorou I, Besson C, Abel L. Combined linkage and association studies show that HLA class II variants control levels of antibodies against Epstein-Barr virus antigens. PLoS One. 2014;9:e102501.

45. Cooper M, van Eeuwijk FA, Hammer GL, Podlich DW, Messina C. Modeling QTL for complex traits: detection and context for plant breeding. Curr Opin Plant Biol. 2009;12:231-40.

46. Holland JB. Genetic architecture of complex traits in plants. Curr Opin Plant Biol. 2007;10(2):156-61

47. Mackay TFC, Stone EA, Ayroles JF. The genetics of quantitative traits: challenges and prospects. Nat Rev Genet. 2009;10:565-77

48. Brauner PC, Melchinger AE, Schrag TA, Utz HF, Schipprack W, Kessel B, Ouzunova M, Miedaner T. Low validation rate of quantitative trait loci for gibberella ear rot resistance in European maize. Theor Appl Genet. 2017;130: 175-86.

49. Dong C, Wu Y, Gao J, Zhou Z, Mu C, Ma P, Chen J, Wu J. Field inoculation and classification of maize ear rot caused by Fusarium verticillioides. Bioprotocol. 2018:8:e3099.

50. Ju M, Zhou Z, Mu C, Zhang X, Gao J, Liang Y, Chen J, Wu Y, Li X, Wang S, Wen J, Yang L, Wu J. Dissecting the genetic architecture of Fusarium verticillioides seed rot resistance in maize by combining QTL mapping and genome-wide association analysis. Sci Rep. 2017;7:46446.

51. Wang Y, Zhou Z, Gao J, Wu Y, Xia Z, Zhang H, Wu J. The mechanisms of maize resistance to Fusarium verticillioides by comprehensive analysis of RNA-seq data. Front Plant Sci. 2016;7:1654

52. Mu C, Gao J, Zhou Z, et al. Genetic analysis of cob resistance to F. verticillioides: another step towards the protection of maize from ear rot. Theor Appl Genet. 2019;132(4):1049-59.

53. Ning $X$, Sun $Y$, Wang $C$, Zhang $W$, Sun $M$, Hu H, Liu J, Yang L. A rice cpyctype glutaredoxin OsGRX20 in protection against bacterial blight, methyl viologen and salt stresses. Front Plant Sci. 2018;9:111.

54. Zhang XC, Yu X, Zhang HJ, Song FM. Molecular characterization of a defense-related AMP-binding protein gene, OsBIABP1, from rice. J Zhejiang Univ Sci B. 2009;10(10):731-9
55. Zhang B, Yuan H, Wang J, Yan H, Shimono M, Day B, Ma Q. TaADF4, an actin-depolymerizing factor from wheat, is required for resistance to the stripe rust pathogen Puccinia striiformis f. sp. tritici. Plant J. 2017:89:1210.

56. Clements MJ, Kleinschmidt CE, Maragos CM, Pataky JK, White DG. Evaluation of inoculation techniques for Fusarium ear rot and fumonisin contamination of corn. Plant Dis. 2003;58 Suppl:C173.

57. Reid LM, Spaner D, Mather DE, Bolton AT, Hamilton RI. Resistance of maize hybrids and inbreds following silk inoculation with three isolates of Fusarium graminearum. Plant Dis. 1993;77:1248-51.

58. Drepper WJ, Renfro BL. Comparison of methods for inoculation of ears and stalks of maize with Fusarium moniliforme. Plant Dis. 1990:74:952-6.

59. Septiani P, Lanubile A, Stagnati L, Busconi M, Nelissen H, Pè ME, Dell'Acqua M, Marocco A. Unravelling the genetic basis of Fusarium seedling rot resistance in the MAGIC maize population: novel targets for breeding. Sci Report. 2019:9:5665.

60. Stagnati L, Lanubile A, Samayoa LF, Bragalanti M, Giorni P, Busconi M, Holland JB, Marocco A. A Genome Wide Association Study Reveals Markers and Genes Associated with Resistance to Fusarium verticillioides Infection of Seedlings in a Maize Diversity Panel. G3 (Bethesda). 2019;9(2):571-9.

61. Kebede AZ, Woldemariam T, Reid LM, Harris $\sqcup$. Quantitative trait loci mapping for Gibberella ear rot resistance and associated agronomic traits using genotyping-by-sequencing in maize. Theor Appl Genet. 2015;129(1): 17-29.

62. Xiang K, Zhang ZM, Reid LM, Zhu XY, Yuan GS, Pan GT. A meta-analysis of QTL associated with ear rot resistance in maize. Maydica. 2010;55(3):281-90.

63. Chen W, Wu JY, Yuan HX. Identification of resistance on maize germplasm to maize ear rot. Maize Science. 2002

64. Reid LM, Mather DE, Bolton AT, Hamilton RI. Evidence for a gene for silk resistance to Fusarium graminearum Schw. Ear rot of maize. J Hered. 1994; 85:118-21.

65. Meng L, Li H, Zhang L, Wang J. QTL IciMapping: integrated software for genetic linkage map construction and quantitative trait locus mapping in bi-parental populations. The Crop Journal. 2015:3:269-83.

66. R Core Team. A Language and Environment for Statistical Computing. R Foundation for Statistical Computing, Vienna, China, 2019. https://www.Rproject.org

67. Elshire RJ, Glaubitz JC, Sun Q, Poland JA, Kawamoto K, Buckler ES, Mitchell SE. A robust, simple genotyping-by-sequencing (GBS) approach for high diversity species. PLoS One. 2011:6:e19379.

68. Glaubitz JC, Casstevens TM, Lu F, Harriman J, Elshire RJ, Sun Q, Buckler ES. TASSEL-GBS: a high capacity genotyping by sequencing analysis pipeline. PLoS One. 2014;9:e90346.

69. Li X, Zhou Z, Ding J, Wu Y, Zhou B, Wang R, Ma J, Wang S, Zhang X, Xia Z, Chen J, Wu J. Combined linkage and association mapping reveals qtl and candidate genes for plant and ear height in maize. Front Plant Sci. 2016;7: 833.

\section{Publisher's Note}

Springer Nature remains neutral with regard to jurisdictional claims in published maps and institutional affiliations.

Ready to submit your research? Choose BMC and benefit from:

- fast, convenient online submission

- thorough peer review by experienced researchers in your field

- rapid publication on acceptance

- support for research data, including large and complex data types

- gold Open Access which fosters wider collaboration and increased citations

- maximum visibility for your research: over $100 \mathrm{M}$ website views per year

At BMC, research is always in progress.

Learn more biomedcentral.com/submission 